\title{
97
}

\section{Technology preparation for preservice teachers: do they feel prepared for 21st century classrooms?}

\author{
Marianne G. Handler \\ Terri Pigott \\ National-Louis University \\ Wheeling, Illinois \\ USA
}

\begin{abstract}
Teachers new to the profession must bring with them the skills needed to integrate technology into their work. Recent studies found preservice programs not providing adequate technology experiences to prepare their students for teaching in 21 st Century classrooms. Perceptions on graduates' preparation to use technology in their own teaching were surveyed. Findings indicate that students who felt prepared, had more experience in methods classes and during student teaching. Respondents indicated a need for experiences with integration strategies, use of application tools and knowledge of a wide range of instructional software. Findings of this nature can assist schools of education as they incorporate technology into existing preservice programs.
\end{abstract}

Main conference themes: teacher education, integration

Educational areas: elementary education, primary education, secondary education

Study topics:

Secondary keywords: computer assisted instruction 


\section{INTRODUCTION}

In many classrooms in today's schools computers and related technologies have brought about changes in the ways students learn and interact with each other. Other schools are struggling to use the little technology available to them to make a difference for their students. Still others are trying to take the first steps to make computers available in their classrooms. Whatever the struggle they all have one question in common. Will new teachers entering their schools be prepared to help them in this restructuring process? Unfortunately, the answer may be 'no' far more often then it will be 'yes'. Criswell [1] found a growing sense of failure in preservice education programs to prepare first-year teachers who feel confident about using computers in their classrooms. Why are these new teachers not prepared? What is or is not happening in colleges and schools of education to prepare preservice teachers to use the technologies which will be in schools in the 21st century? And how well prepared do current new teachers feel to use the computers and other technologies which are available in schools?

The need to prepare preservice teachers to integrate technology into the range of instructional strategies they bring to their teaching, is not a new concern and has been addressed in the literature in a variety of articles (Criswell [1], Handler [2], Jongejan [3]). These researchers urge that preservice teachers should have experiences to make them comfortable with the use of computers and develop the ability to integrate technology as an instructional tool. Although in $198789 \%$ of teacher education programs offered some computer training opportunities for their preservice students, only $29 \%$ of the respondents to a national survey of education majors saw themselves as prepared to teach with computers (US Congress OTA [4]). In this same survey $50 \%$ of teacher education faculty believed that their students were adequately prepared to go into schools where computers, the main technology of that time, were being used. Other studies have found that experiences with computers in elementary education preservice programs appear to be inadequate to train teachers who feel prepared for 21st century classrooms (Handler [5], Ingram [6]).

Today the computer is no longer the only technology in schools. Telecommunications, hypermedia, CD-ROM players and many peripheral devices which support the use of multimedia are available to provide new learning environments for students. How are teacher education programs restructuring their curricula to integrate technology experiences into the student experience? How do today's graduates perceive themselves as compared to the 1987 study (US Congress OTA [4]). Have teacher education programs begun to reflect awareness of the International Society for Technology in Education 
(ISTE) technology use foundation standards [7] which are now guidelines for National Collegiate Accreditation of Teacher Education (NCATE) during reviews of teacher education programs?

\section{METHODS}

\section{Procedures}

Colleges and schools of education near a major metropolitan area in the Midwest region of the United States were asked to participate in a survey of their 1991 teacher education graduates. Targeted graduates had completed one year of teaching experience and were beginning a second year of teaching at the time of the survey. Six institutions agreed to participate. Five institutions provided mailing labels to the researchers. The sixth institution placed the labels on the surveys to their own graduates due to the privacy issue. Initially 998 surveys were mailed followed by a second mailing to those who did not respond. Ultimately 61 surveys were returned with no known forwarding address. Of the total 937 surveys with accurate addresses 226 were returned resulting in a $24 \%$ response rate. Warwick and Lininger [8] indicate that mail questionnaires generally have a low completion rate and a $40-50 \%$ response rate is considered exceptional. The researcher's own institution had the highest individual response rate $(30.7 \%)$ while the lowest response rate $(10.3 \%)$ came from another private institution. Because of the low response rate results from the survey cannot be generalized to all recent teacher education graduates from these six institutions. Instead, the results are descriptive only of those who responded to the survey.

\section{Survey}

The survey was a revised form of an instrument used by Handler [5]. The survey was designed to gather the perceptions of recent teacher education graduates on their exposure to computer experiences throughout their teacher education program and their preparation to use technology in the classroom. For those respondents now teaching the survey also elicited information about their current use of computers and other technology. The survey included both closed and open ended questions about computer experiences during undergraduate work, teacher education course work and observation and the use of the computer during preclinical hours and student teaching. Respondents were also asked to indicate if they were willing to respond to a follow up telephone interview. Twenty-six of the respondents were interviewed by telephone to provide more detailed information about their experiences with technology. 


\section{Sample}

Most (61\%) of the respondents were completing undergraduate preservice programs from their respective teacher education program. Most were female (79\%) ranging in age from 20 to over 40 with more than half $(53 \%)$ in the 20 29 age range. A majority $(80 \%)$ of the respondents had an elementary school teaching certificate with $11 \%$ indicating early childhood and another $8 \%$ holding secondary certification. Of the 226 respondents $177(78 \%)$ currently hold teaching positions. Of those currently teaching $65 \%$ were in $\mathrm{K} 5$ classrooms (primary education), $24 \%$ in 6-12 classrooms (secondary education) and $10 \%$ in early childhood settings (elementary education). About half $(53 \%)$ of the respondents taught in suburban schools with $31 \%$ in urban settings and $16 \%$ in rural districts.

\section{RESULTS}

This paper will focus on the respondents' perception of the preparation they received in their teacher education program for using technology in their teaching. Only response from the 177 students currently teaching are utilized in this study. Of the 177 respondents only $28(16 \%)$ indicated that they felt adequately to thoroughly prepared in their preservice program for using computers as an instructional tool. Most (84\%) felt only minimally prepared or unprepared to use computers in the classroom. The following sections explore the differences between those graduates who felt prepared to use technology in their classroom and those who felt unprepared.

\section{Computer use during teacher education program}

A majority $(81 \%)$ of those who felt prepared indicated that their teacher education program offered an introductory course on the use of computers and other technologies in education and, as seen in Figure 1, most of those with the opportunity took the course. Of those who felt unprepared, only $49 \%$ indicated that an introductory course was offered and, as seen in Figure 1, only $54 \%$ enrolled in the course when offered.

When asked whether the course was of value all of the prepared group indicated it was of some or great value, while $54 \%$ of the unprepared group thought that the course had at least some value.

Overall $116(51 \%)$ of all respondents saw the computer used in at least one methods course. About half (49\%) of the unprepared group and a majority $(68 \%)$ of the prepared group saw the computer utilized in at least one methods course. As seen in Figure 2 most students participated in software evaluation or word processing. 
Technology preparation for preservice teachers: do they feel prepared for 21st 1049 century classrooms?

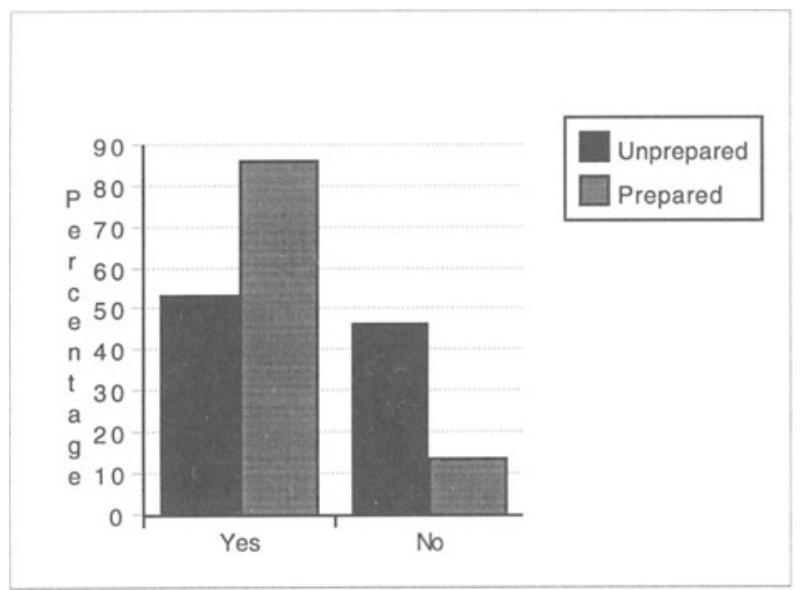

Fig. 1 Introductory course taken

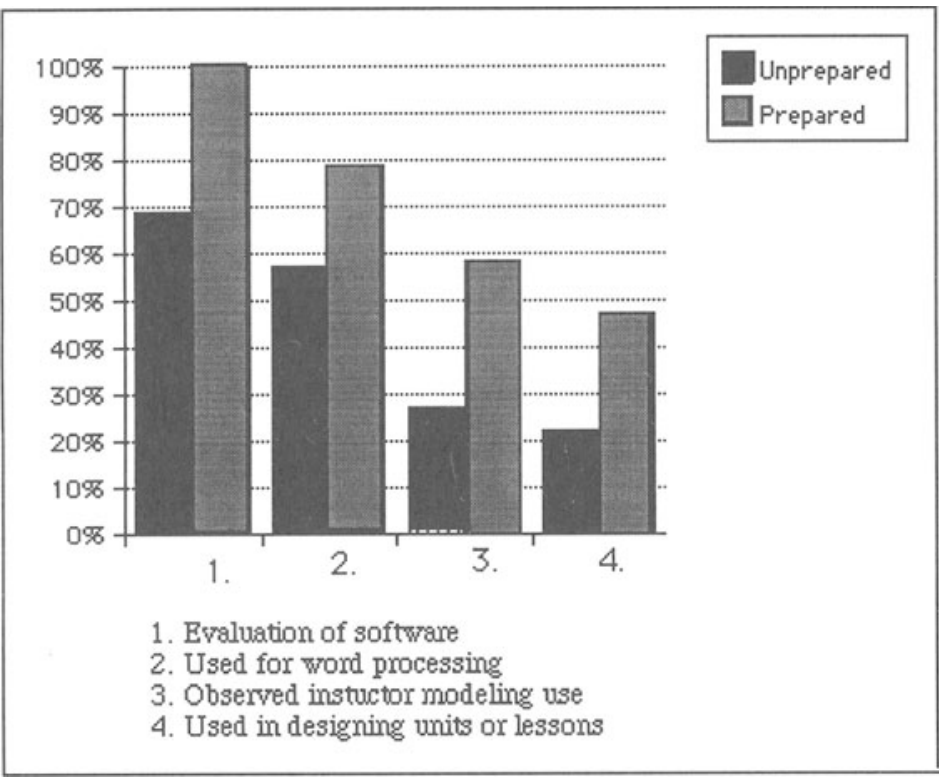

Fig. 2 Computer activities in content area or methods courses

Few students saw instructors modelling the use of technology. Even fewer students were required to incorporate technology into a lesson plan. More 
students who felt prepared, participated or observed these activities in methods classes than unprepared students.

Responses to open ended questions indicated no in depth experiences with technology during these courses. Students referred to demonstrations of content area software in methods classes, teacher utilities and demonstrations of statistical software. The only hands on courses appeared to be in the area of software evaluation. There is no mention of the instructor modelling the use of technology with specific instructional strategies.

\section{Computer use in preclinical and student teaching experiences}

Of the teachers who felt prepared $46 \%$ indicated that they often or consistently observed the computer or other technology used in instructional settings during their preclinical experience. Only $18 \%$ of the total of 148 students who did not feel prepared, observed computer use during preclinical hours though overall these occasions were few. Thirty-nine percent of the prepared groups and $7.5 \%$ of the unprepared group had a chance to use the computer in an instructional setting during preclinical experiences.

These differences between the groups persist in student teaching placements. Figure 3 shows that neither group observed much computer use though those who felt prepared, saw more than the unprepared group. Figure 4 also indicates that while the majority of both groups had little opportunity to use the computer during student teaching, more of the prepared group used the computer than those in the unprepared group.

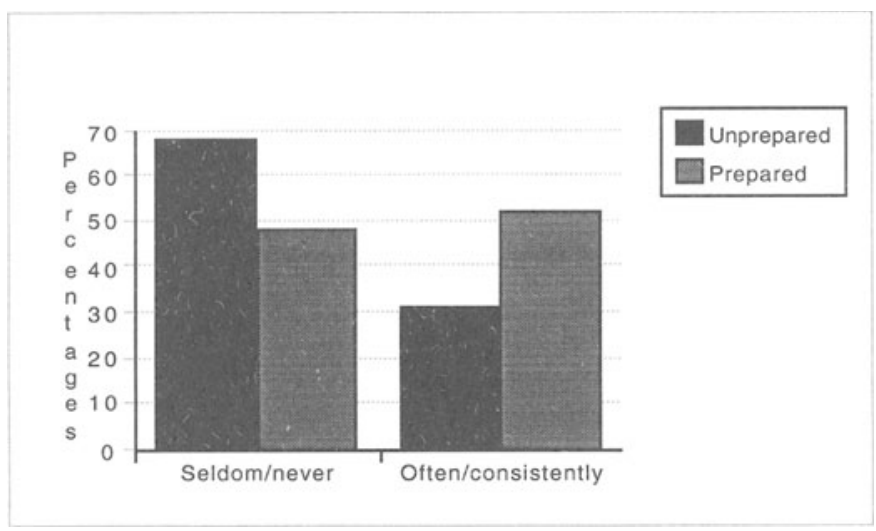

Fig. 3 Computer use observed during student teaching 


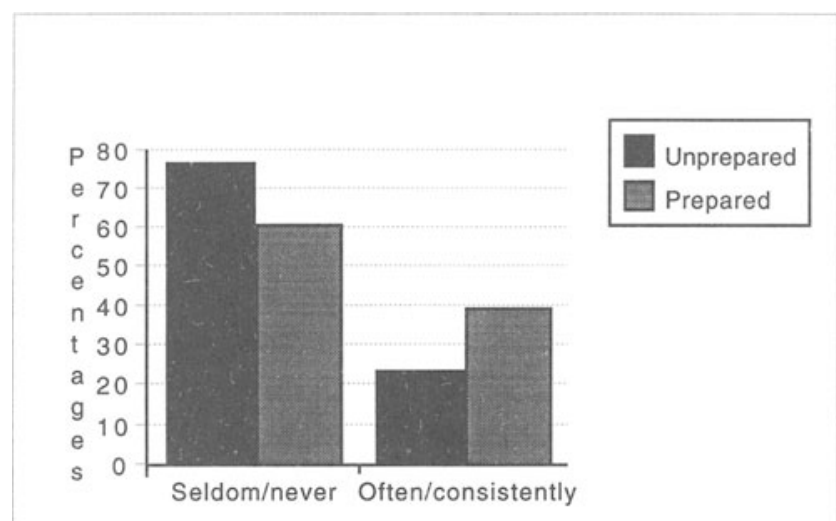

Fig. 4 Computers used during student teaching

When asked to describe their student teaching experiences respondents often observed students going to computer labs where instruction was rarely linked to the curriculum. Some quality integrated experiences were observed such as exposure to sessions using the National Geographic Acid Rain project or the Sunburst Voyage of the Mimi. Respondents frequently noted that, although there might be a computer in the classroom, the cooperating teacher rarely used it.

\section{Current use of the computer in the first year of teaching}

When asked about their current use of the computer in their classrooms, those who felt prepared were more likely to indicate that they incorporated the computer into their teaching. As seen in Figure 5 more of the prepared group were expected to use the computer for instruction on a regular basis than the unprepared group.

More of the prepared group also used the computer for introducing new materials and for integrating the use of the computer into their instruction.

When respondents were asked to suggest experiences for future preservice students, several major areas emerged:

- knowledge of ways to integrate technology into the curriculum;

- development of comfort with application tools;

- exploration of content area software which would help with collaboration experiences and higher order thinking skills. 


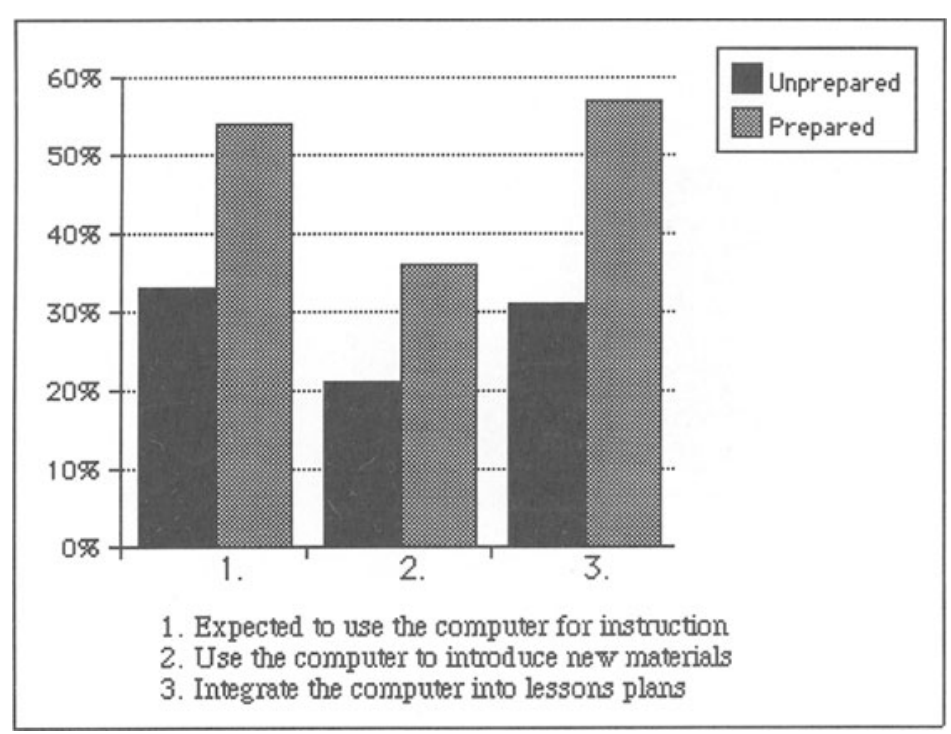

Fig. 5 Computer uses in current teaching position

\section{DISCUSSION}

From the responses to this survey two point arise. First, beginning teachers in this survey who feel prepared to use technology, report having more opportunities to use and observe computers during their preservice methods classes and student teaching experiences. Second, even these teachers did not indicate that these opportunities occurred with great frequency. This recognition of lack of opportunity for preservice teachers to have extended experiences has been noted in other studies (Bosch and Cardinale [9], Handler [5]).

Few respondents indicated comfort or experiences in the areas listed in the ISTE Foundation Standard Curriculum guidelines for Accreditation [7]. While most appear to be personal users (Foundation Standard 9) and many had experiences evaluating software (Foundation Standard 2), few teachers currently integrate computers into their work (Foundation Standards 4, 5, 6, and 7). The remaining standards were not noted at all. 
Jongejan [3] listed the two specific recommendations made in 1986 for activities which should take place for preservice teachers:

- 10 prospective teachers should learn about the use of technology in their curriculum areas;

- schools of education should develop relationships with K12 (secondary) schools which use technology to provide internships for these prospective teachers.

Clearly these ideas are still relevant and unaddressed. What direction must be taken to create conditions in which we better prepare our new teachers? To meet the recommendations of the 1986 national Governors Association Task Force on Technology (as cited in Jongejan [3]), there are steps which can be taken even today.

More experiences in methods and curriculum area courses must be provided. It is evident that care must be taken in the selections of classrooms where student teachers will be placed, so that they may have opportunity to see the computer used with children as an instructional tool. Gooler [10] emphasizes the importance of preservice teachers having real experiences with technology in classrooms. The ISTE Foundation Standards provide guidelines which schools of education could use as they integrate technology experiences within their programs.

Asking faculty to begin this process requires professional development at the university level. Designing and developing appropriate technology experiences means that the faculty themselves must develop comfort with and an awareness of the technology which is currently being used in schools. More importantly it means that education faculty must model the use of technology in their own teaching (Novak and Knowles [11]). It is hard to forget Lortie's [12] admonition that we teach as we are taught.

The current literature and the perceptions of teachers described in this study suggest several directions for further research. Most of the literature addresses how preservice teachers view their own technology use in the classroom. What does appear to have been examined to date are the perceptions of those in elementary education departments. In $198750 \%$ of the faculty responding believed their students were being prepared (US Congress OTA [4]). Do the faculty believe that today? Faculty members' perceptions of their students' preparation would provide information complementary to the studies about student's perceptions of their preparation to use technology. Further studies also are needed which examine what schools of education are doing to bring technology into their programs in a meaningful way and the criteria and processes for placement of student teachers. 


\section{ACKNOWLEDGEMENT}

This project was partially funded by a grant from Phi Delta Kappa.

\section{REFERENCES}

1. Criswell, J. R. (1989) Rethinking microcomputer instruction as a part of teacher education reform. Educational Technology, 29 (11) pp. 40-3.

2. Handler, M. (1992) Successful strategies for increasing technology in preservice programs, in Technology and Teacher Education Annual 1992, AACE, Charlottesville, Virginia, USA, pp. 326-328.

3. Jongejan, T. (1990) Teacher training for technology education in schools of education. Journal of Computing in Teacher Education, 7 (1) pp. 3-11.

4. U. S. Congress (1988) Power on!: New tools for teaching and learning. OTA-SET, 379, Office of Technology Assessment, Washington, D.C., U. S.A .

5. Handler, M. (1993) Preparing new teachers to use computer technology: Perceptions and suggestions for teacher educators. Computers and Education, 20 (2) pp. 147-156.

6. Ingram, J. M. (1992) Who's teaching the teacher: Elementary education and the computer. Journal of Computing in Teacher Education, 8 (3) pp. 1719.

7. Curriculum Guidelines for Accreditation of Education Computing and Technology Programs (1992) International Society for Technology in Education, Eugene, OR, USA

8. Warwick, D. P. and Lininger, C. A. (1975) The Sample Survey: Theory and Practice. McGraw-Hill, New York, NY, USA

9. Bosch, K. A. and Cardinale, L. (1993) Pre-service teachers' perceptions of computer use during field experience. Journal of Computing in Teacher Education, 10 (1) pp. 23-27. 
Technology preparation for preservice teachers: do they feel prepared for 21st 1055 century classrooms?

10. Gooler, D. (1989) Preparing teachers to use technologies: Can universities meet the challenge? Educational Technology, 29 (3) pp. 18-21.

11. Novak, D. and Knowles, J. K. (1991) Beginning elementary teachers' use of computers in classroom instruction. Action in Teacher Education, 13 (2) pp. $43-48$.

12. Lortie, D. (1977) Schoolteacher. University of Chicago Press, Chicago, IL, USA. 